\title{
Potencial alelopático e identificação dos metabólitos secundários em extratos de Canavalia ensiformis $\mathrm{L}^{1}{ }^{1}$
}

\author{
Juliana Campana Pereira ${ }^{2 *}$, Cynthiane Lins de Albuquerque Paulino ${ }^{3}$, Bruna da Silva Granja ${ }^{4}$, \\ Antônio Euzébio Goulart Santana ${ }^{4}$, Laurício Endres ${ }^{5}$, Renan Cantalice de Souza ${ }^{6}$
}

$10.1590 / 0034-737 X 201865030004$

\begin{abstract}
RESUMO
As espécies que apresentam potencial alelopático são promissoras na agricultura, ante a perspectiva da identificação e manipulação dos seus metabólitos secundários, para aplicações práticas e, assim, sua utilização no controle de plantas daninhas. Por esta razão, este trabalho teve por objetivo verificar o efeito alelopático e identificar os metabólitos secundários de Canavalia ensiformis L. Sementes de Lactuca sativa, Digitaria insularis, Emilia coccinea e Portulaca oleracea foram utilizadas como receptoras. Para avaliar o potencial alelopático, foi preparado o extrato etanólico da parte aérea (folhas mais caules) da espécie doadora. Os efeitos potencialmente alelopáticos foram avaliados por meio de testes de germinação e crescimento inicial de plântulas. Foi realizada, também, por meio da técnica da Cromatografia Líquida de Alta Eficiência, a identificação dos metabólitos secundários da parte aérea de C. ensiformis. O extrato etanólico causa inibição da percentagem e do índice de velocidade de germinação de $L$. sativa. A parte aérea de $C$. ensiformis contém ácidos fenólicos (ácido clorogênico, ácido ferúlico, ácido cafeico), flavonoides (kaempferol, naringina e rutina) e ácidos carboxílicos (ácido cítrico, ácido malônico e ácido aspártico), podendo ser os responsáveis pela atividade alelopática dessa espécie.
\end{abstract}

Palavras-chave: alelopatia; feijão-de-porco; fitoquímica.

\section{ABSTRACT}

\section{Allelopathic potential and identification of secondary metabolites in extracts of Canavalia ensiformis L.}

Species that have allelopathic potential are promising in agriculture, with the perspective of identifying their secondary metabolites and manipulating them, for practical applications and, thus, be used to control weeds. In this context, this work aimed to verify the allelopathic effect and identify the secondary metabolites in Canavalia ensiformis species. The Lactuca sativa, Digitaria insularis, Emilia coccinea, and Portulaca oleracea species were used as recipient species. To evaluate the allelopathic potential, the ethanolic extract of the shoot (leaf + stem) of the donor species was carried out. Potential allelopathic effects were evaluated by germination tests and initial seedling growth. The identification of the secondary metabolites of the C. ensiformis shoot was also performed using the high-performance liquid chromatography technique. The ethanolic extract causes germination inhibition and germination speed index of L. sativa. The $C$. ensiformis shoot contains the compounds belonging to phenolic acids (chlorogenic acid, ferulic acid, and caffeic acid), flavonoids (kaempferol, naringin, and rutin), and carboxylic acids (citric, malonic, and aspartic acids), which can be responsible for the allelopathic activity of this species.

Keywords: allelopathy; jack bean; phytochemical.

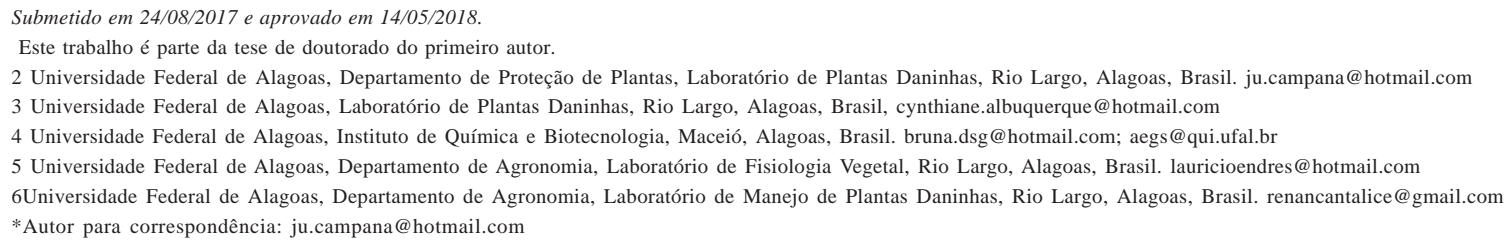




\section{INTRODUÇÃO}

As plantas daninhas causam impacto direto na agricultura, por causa dos custos de controle com mão de obra, equipamentos, herbicidas, entre outros. Essas plantas afetam indiretamente, por serem hospedeiras de pragas e doenças, competem com a cultura de interesse econômico pelos recursos do meio, reduzindo a produtividade e elevando os custos de produção (Zimdahl, 2007). Assim, é necessário seu manejo adequado para diminuir os prejuízos que causam. Apesar da contribuição significativa dos métodos convencionais de controle de plantas daninhas, na melhoria da produtividade das culturas, certos desafios também estão associados a eles, tornando cada vez mais necessárias opções de manejo diversificadas. A pesquisa com espécies que apresentem potencial alelopático está cada vez mais em evidência na perspectiva da sua manipulação, para aplicações práticas na agricultura e, assim, serem utilizadas no controle de plantas daninhas (Jabran \& Farooq, 2013; Zeng, 2014).

O feijão-de-porco (Canavalia ensiformis), pertencente à família Fabaceae, é uma espécie muito cultivada como adubação verde e suas raízes apresentam associação simbiótica com bactérias fixadoras de nitrogênio (Blum, 1995; Cavalcanti, 2011). É cultivado em regiões quentes, com clima tropical e subtropical, sendo encontrado em sua forma silvestre nas Antilhas e em zonas tropicais africanas e asiáticas (Calegari, 1995). Há relatos de que a espécie exerce efeitos alelopáticos por meio da inibição da germinação e crescimento de plântulas (Souza Filho, 2002; Santos et al., 2005; Mendes \& Rezende, 2014).

Os responsáveis por efeitos prejudiciais nas plantas são os aleloquímicos, presentes em várias partes da planta. São resultantes do metabolismo secundário e capazes de causar os efeitos alelopáticos sobre o metabolismo de espécies receptoras (Taiz \& Zeiger, 2013). Estes metabólitos estão divididos em três principais grupos: compostos fenólicos, terpenos e alcaloides (Ferreira \& Áquila, 2000; Rice, 2013). Os compostos fenólicos são as substâncias químicas mais comumente associadas com o efeito alelopático (Taiz \& Zeiger, 2013). Classificam-se em ácidos fenólicos, flavonoides, fenóis simples, cumarinas, taninos e ligninas (Shahidi \& Naczk, 1995; Larcher, 2000). Os ácidos fenólicos atuam induzindo o aumento da atividade de enzimas oxidativas, causando assim, modificações da permeabilidade da membrana e a formação de lignina, contribuindo para a redução do crescimento radicular da planta (Ferrarese et al., 2000; Bubna et al., 2011; Oliveira et al., 2011). Os flavonoides são os compostos naturais mais presentes nas plantas e apresentam efeitos alelopáticos capazes de inibir a germinação e o crescimento de plantas (Hoagland \& Williams, 2004; Bais et al., 2006; Buer \& Djordevic, 2009; Franco et al., 2016).
Um dos métodos utilizados para identificar esses compostos é a Cromatografia Líquida de Alta Eficiência (HPLC), técnica utilizada para separações e análises quantitativas de vários metabólitos secundários, em tempo reduzido, com alta resolução, eficiência e sensibilidade (Collins et al., 2006).

O objetivo deste trabalho foi verificar o efeito alelopático e identificar os metabólitos secundários presentes na parte aérea de Canavalia ensiformis.

\section{MATERIAL E MÉTODOS}

O experimento foi realizado no Centro de Ciências Agrárias (CECA), da Universidade Federal de Alagoas (UFAL), situado em Rio Largo, Alagoas (9²7' S, 35 27' O, a $127 \mathrm{~m}$ de altitude). Foi utilizada $C$. ensiformis como espécie doadora. para se avaliar o possível potencial alelopático. As sementes de C. ensiformis foram adquiridas da BRSeeds ${ }^{\circledR}$ (lote número 2342/13). O extrato foi obtido da parte aérea (caule mais folhas) de plantas de $C$. ensiformis, coletadas com três meses de idade, quando as plantas atingiram a fase de floração. O material foi secado em estufa de circulação de ar forçada, a $60{ }^{\circ} \mathrm{C}$, por $72 \mathrm{~h}$. Após esse processo, o material desidratado foi triturado em moinho de facas "tipo willey" com peneira 30 Mash, até a obtenção de fragmentos menores, resultando em $250 \mathrm{~g}$ de material de parte aérea (adaptado de Hagemann et al., 2010).

Para a preparação do extrato etanólico, o material foi submerso em álcool etílico 95\%, na proporção de 1:5 (p/ v), agitado e mantido em temperatura ambiente por 72 horas, após o que foi filtrado e o resíduo do material foi novamente extraído com o mesmo solvente, por mais 72 horas. Esse processo foi repetido várias vezes até a obtenção de uma extração límpida. O extrato filtrado resultante e todas as extrações foram reunidos e concentrados, em rotaevaporador de pressão reduzida, em temperatura média de $50^{\circ} \mathrm{C}$, obtendo-se, assim, 15,82 g de extrato. Para a obtenção das concentrações de $1,25 \mathrm{mg} \mathrm{ml}^{-1} ; 2,50 \mathrm{mg}$ $\mathrm{ml}^{-1} ; 5,00 \mathrm{mg} \mathrm{ml}^{-1} ; 10,00 \mathrm{mg} \mathrm{ml}^{-1}$ e $20,00 \mathrm{mg} \mathrm{ml}^{-1}$, o extrato bruto foi solubilizado, adicionando-se $0,1 \%$ de DMSO (dimetilssulfóxido) e água destilada, utilizando-se ultrassom até a completa solubilização. Foi utilizada a testemunha com água mais DMSO (adaptado de Al-Sherif et al., 2013).

Foi realizado o delineamento inteiramente casualizado, com quatro repetições, em concentrações crescentes, visando a observar o efeito alelopático em diferentes espécies receptoras. Os efeitos potencialmente alelopáticos do extrato etanólico de $C$. ensiformis foram avaliados por meio de testes de germinação, índice de velocidade de germinação e crescimento inicial de plântulas. Como receptoras foram utilizadas a Lactuca sativa (alface) e as 
espécies daninhas Digitaria insularis (Capim amargoso), Emilia coccinea (Falsa-serralha) e Portulaca oleracea (Beldroega). Foram selecionadas espécies que apresentam germinação rápida e uniforme e consideradas sensíveis, possibilitando que os resultados se expressem sob baixas concentrações do extrato (Ferreira \& Áquila, 2000).

Germinação: testes de germinação foram conduzidos em caixas plásticas transparentes, tipo gerbox com tampa (11x11x4cm) e forradas com duas folhas de papel germitest. O papel foi umedecido com $6 \mathrm{~mL}$ de cada extrato e, sobre ele, depositadas 30, 50 e 200 sementes de L. sativa (cultivar "Baba de Verão") e $D$. insularis, E. coccinea e $P$. oleraceae, respectivamente. As caixas foram mantidas em câmara climatizada, tipo BOD (Demanda Bioquímica de Oxigênio), sob temperatura de $25^{\circ} \mathrm{C}$ e fotoperíodo de 12 horas, para a espécie L. sativa, e sob temperaturas alternadas de 20 a $30^{\circ} \mathrm{C}$, com fotoperíodo de 12 horas, para as espécies de plantas daninhas (D. insularis, E. coccinea e P. oleraceae) (Brasil, 2009, Lessa et al., 2013). A cada 24 horas, as sementes foram avaliadas para verificar a protrusão radicular, conforme Borghetti \& Ferreira (2004). Ao final do tempo experimental, aos sete dias da semeadura, para as espécies $L$. sativa e D. insularis, e aos 14 dias, para E. coccinea e $P$. oleraceae, as plântulas foram avaliadas quanto ao desenvolvimento da radícula e da parte aérea, e classificadas em normais (Brasil, 2009). Indice de velocidade de germinação (IVG): os dados verificados nas contagens diárias, realizadas no teste de germinação, foram utilizados para cálculo do IVG. Os dados foram tabulados e calculados, segundo a equação de Maguire (1962). Comprimento de Plântulas: avaliado em conjunto com o teste de germinação, utilizando-se as plântulas normais e avaliando-se o comprimento da parte aérea (CPA) e da raiz primária (CRA), por meio de régua milimetrada.

\section{Partição líquido-líquido}

Foi realizada com o extrato bruto etanólico da parte aérea de C. ensiformis, com diferentes solventes, para determinar a melhor fração a ser utilizada nos testes de Cromatografia Líquida de Alta Eficiência. Inicialmente, 12,5 $\mathrm{g}$ do extrato bruto foi suspenso com $250 \mathrm{~mL}$ de Metanol, em um funil de separação, e adicionado o solvente nHexano, para a extração ( 3 x $250 \mathrm{~mL}$ ). Após esse processo, foi retirada a fração hexânica, sendo a fração metanólica suspensa em água $(250 \mathrm{~mL})$, e submetida a partição com Clorofórmio ( 3 x $250 \mathrm{~mL}$ ). Foi retirada a fração clorofórmica e, na fração metanólica mais água, foi adicionado Acetato de Etila (3 x $250 \mathrm{~mL})$.

Para a determinação da fração mais ativa, foi selecionada a concentração mais próxima que inibiu $50 \%$ da germinação da espécie L. sativa $\left(2,5 \mathrm{mg} \mathrm{mL}^{-1}\right)$, e realizados testes de germinação e de crescimento de plântulas.

\section{Cromatografia Líquida de Alta Eficiência (HPLC)}

Para verificar a existência de compostos no extrato da parte aérea de $C$. ensiformis, foram selecionados alguns padrões, já identificados em estudos anteriores, com a mesma espécie, e comparados com os presentes na amostra: flavonoides (kaempferol, quercetina, rutina e naringina), ácidos fenólicos (ácido ferúlico, ácido clorogênico e ácido cafeico) e ácidos carboxílicos (ácido cítrico, ácido malônico e ácido aspártico) (Santos et al., 2007; Mendonça, 2008).

Parâmetros do HPLC: foi utilizado um cromatógrafo líquido da marca Shimadzu® (Kyoto, Japan), equipado com um degaseificador (DGU-20A3), com autoinjetor (SIL-20A HT), duas bombas LC-10AD e detector de arranjos de diodos (SPD-M20A). As amostras foram analisadas em uma coluna cromatográfica C18 (5 ìm, 4.6× $250 \mathrm{~mm}$ ). Os dados resultantes foram adquiridos e analisados pelo software Lab Solution versão 1.25 SP5 (Shimadzu). A temperatura da coluna foi mantida em 25 ${ }^{\circ} \mathrm{C}$ e o eluente foi verificado nos comprimentos de onda na gama de 190-540 nm. Foram utilizadas duas metodologias para a fase móvel. Na primeira, para detectar a presença dos padrões pertencentes aos flavonoides (kaempferol, quercetina, rutina e naringina) e ácidos fenólicos (ácido ferúlico, ácido clorogênico e ácido cafeico), foi utilizada uma fase móvel isocrática com $0,1 \%$ $\mathrm{H}_{3} \mathrm{PO}_{4}: \mathrm{CH}_{3} \mathrm{OH}(80: 20)$, taxa de fluxo: $1 \mathrm{mg} \mathrm{mL}^{-1}$, volume de injeção: $20 \mu \mathrm{L}$ e tempo de corrida: $12 \mathrm{~min}$ (adaptado de Hajimehdipoor et al., 2012). Na segunda, para os padrões pertencentes aos ácidos carboxílicos (ácido cítrico, ácido malônico e ácido aspártico), foi utilizada na fase móvel isocrática uma solução de $10 \mathrm{mM} \mathrm{KH}_{2} \mathrm{PO}_{4}: \mathrm{CH}_{3} \mathrm{OH}(95: 5$, pH 2,7), taxa de fluxo: $0,8 \mathrm{ml} / \mathrm{min}$, volume de injeção: $10 \mu \mathrm{L}$ e tempo de corrida: 15 min (adaptado de Ding et al., 2006). A identificação dos compostos presentes na amostra deuse por comparação com o tempo de retenção dos cromatogramas da amostra de $C$. ensiformis com os padrões, para isso, todos foram preparados nas mesmas condições.

O comprimento de onda foi definido para cada padrão de acordo com a melhor visualização do pico. A partir dessa verificação, para os padrões ácido cafeico, kaempferol, ácido cítrico, ácido malônico e ácido aspártico, a melhor visualização do pico foi verificada a $220 \mathrm{~nm}$. Para a naringina, a $270 \mathrm{~nm}$. Ácido clorogênico e ácido ferúlico foram identificados no comprimento de onda de $330 \mathrm{~nm}$. E a rutina, a $360 \mathrm{~nm}$.

Preparo das amostras e padrões: para o preparo da amostra de $C$. ensiformis, foi utilizada a fração Acetato de etila, obtida por partição líquido-líquido do extrato bruto etanólico de $C$. ensiformis. A amostra foi solubilizada em 
metanol (0,1 mg mL-1) e filtrada em membrana de 0,45 $\mu \mathrm{m}$. $\mathrm{O}$ mesmo procedimento foi realizado para os padrões com concentrações diferentes: ácido clorogênico, ácido ferúlico e rutina: $0,1 \mathrm{mg} \mathrm{mL}^{-1}$; ácido cafeico e quercetina: $0,05 \mathrm{mg}$ $\mathrm{mL}^{-1}$; kaempferol e naringina: 0,2 $\mathrm{mg} \mathrm{mL}^{-1}$; ácido cítrico, ácido malônico e ácido aspártico: $1 \mathrm{mg} \mathrm{mL}^{-1}$.

Os dados obtidos, referentes às concentrações, foram averiguados por aplicação do teste $\mathrm{F}$ sobre a análise da variância. Sendo significativo o efeito do extrato, para determinar a $\mathrm{CL}_{50}$ (concentração inibitória equivalente a $50 \%$ de efeito em relação à testemunha), os dados foram ajustados ao modelo de regressão não linear do tipo logístico, com três parâmetros (Streibig, 1988), utilizandose o programa Sigmaplot:

$y=\frac{a}{\left[1+\left(\frac{x}{b}\right)^{\mathrm{c}}\right]}$

em que: $y=$ controle percentual; $x=$ concentração do extrato; $a, b$, e $c$, parâmetros estimados da equação, de forma que $a=$ amplitude existente entre o ponto máximo e o ponto mínimo da variável, $b=$ concentração que proporciona $50 \%$ de resposta da variável e $c=$ declividade da curva ao redor de $b$.

O modelo logístico apresenta vantagens, uma vez que um dos termos integrantes da equação $(b)$ é uma estimativa do valor de $\mathrm{CL}_{50}$ (Christoffoleti, 2002). $\mathrm{CL}_{50}$ é a concentração do extrato que proporciona o valor de $50 \%$ de controle ou de redução de crescimento da espécie receptora (adaptado de Christoffoleti, 2002; Christoffoleti \& LópezOvejero, 2008).

Os valores da testemunha foram considerados como $100 \%$, sendo os resultados de cada variável dos demais tratamentos calculados em relação à testemunha:

$\operatorname{VR}(\%)=100 \frac{V}{T m}$

em que: $\mathrm{VR}=$ variável em relação à testemunha $(\%) ; \mathrm{V}=$ variável analisada (G, IVG, CPA ou CRA); Tm = média da testemunha $(\%)$.

\section{RESULTADOS E DISCUSSÃO}

Pelas curvas de dose-resposta, pode-se observar, com mais clareza, maior sensibilidade das espécies receptoras L.sativa, D. insularis, E.coccinea e P. oleraceae aos aleloquímicos presentes no extrato, definindo-se a concentração inibitória equivalente a 50\% de efeito em relação à testemunha $\left(\mathrm{CL}_{50}\right)$ (Tabela 1$)$. Conforme o incremento das concentrações, ocorreu a inibição da germinação em todas as espécies, indicando possível efeito alelopático do extrato (Figura 1-A). A sensibilidade da germinação ao extrato obedece à seguinte ordem: L. sativa $>$ P. oleraceae $>$ D. insularis $>$ E. coccinea, com $\mathrm{CL}_{50}$ de $1,24 \mathrm{mg} \mathrm{ml}^{-1}>$
$1,82 \mathrm{mg} \mathrm{ml}^{-1}>3,41 \mathrm{mg} \mathrm{ml}^{-1}>4,39 \mathrm{mg} \mathrm{ml}^{-1}$, respectivamente (Tabela 1). Para o índice de velocidade de germinação (IVG) (Figura 1-B), todas as espécies receptoras também apresentaram redução com o incremento da concentração, sendo L. sativa a mais sensível $\left(\mathrm{CL}_{50}=1,59 \mathrm{mg} \mathrm{ml}^{-1}\right)$, e $P$. oleraceae a mais tolerante $\left(\mathrm{Cl}_{50}=6,56 \mathrm{mg} \mathrm{ml}^{-1}\right)$ (Tabela 1$)$. Corroborando esses resultados, Silva et al., (2010), ao avaliarem o potencial alelopático do extrato etanólico das folhas de Anadenanthera macrocarpa (Fabaceae) e de Astronium graveolens (Anacardiaceae), na germinação de Brassica chinensis e de L. sativa, verificaram que os extratos apresentaram potencial alelopático, independentemente da concentração utilizada, mas com resposta dose-dependente, sendo, assim, capaz de interferir diretamente na germinação e no índice de velocidade de germinação.

Entre as espécies receptoras, constataram-se diferenças do efeito alelopático sobre a germinação, corroborando resultados de Marinov-Serafimov (2010), que relatou diferenças na inibição de plantas daninhas submetidas ao extrato de leguminosas. As diferenças na sensibilidade das espécies receptoras ocorrem por causa de diferentes mecanismos de absorção, translocação e sítio ativo dos compostos alelopáticos, podendo essa sensibilidade ser alterada de acordo com a concentração do extrato, condições ambientais e estádio de desenvolvimento da planta (Weir et al., 2004; Taiz \& Zeiger, 2013). A variação do local de ação dos aleloquímicos nas espécies receptoras pode explicar as diferenças de seletividade entre as espécies analisadas neste experimento. Similarmente a esses resultados, Taveira et al., (2013) observaram que os extratos etanólicos das folhas de plantas do gênero Erythroxylum spp. promoveram reduções significativas da germinação de Lycopersicum esculentum e Allium cepa.

O efeito alelopático pode ser visualizado em outras variáveis e não apenas na percentagem de germinação. Para Ferreira \& Áquila (2000), a germinação é menos sensível aos metabólitos secundários do que o crescimento das plântulas. O extrato etanólico de C. ensiformis contribuiu para a diminuição do comprimento da parte aérea (Figura 1-C) e radicular (Figura 1-D), mais intensamente, à medida que se aumentou a concentração, a partir da de $5,00 \%$, indicando que o efeito alelopático do extrato das plantas é dependente das concentrações.

P. oleraceae apresenta $\mathrm{CL}_{50}$ menor que o das outras espécies receptoras $\left(\mathrm{CL}_{50=} 2,79 \mathrm{mg} \mathrm{ml}^{-1}\right)$ para inibir o comprimento da parte aérea, enquanto, para a parte radicular da plântula, ela se mostrou mais tolerante que as outras espécies com $\mathrm{CL}_{50}=3,65 \mathrm{mg} \mathrm{ml}^{-1}$ (Tabela 1). Diferindo dos resultados observados para a espécie $P$. oleraceae, há trabalhos que relatam que a parte radicular da plântula geralmente é mais sensível aos aleloquímicos, quando comparada com outras estruturas da plântula, por causa 
do contato direto e prolongado das raízes com o extrato, ou por respostas fisiológicas distintas entre estruturas (Ferreira \& Áquila, 2000; Chon et al., 2003). Souza Filho (2002) comprovou que extratos hidroalcoólicos da parte aérea, raízes e sementes de Canavalia ensiformis exerceram efeitos alelopáticos sobre a germinação de sementes e sobre o crescimento radicular das plantas daninhas $\mathrm{Mi}$ mosa pudica, Urena lobata, Senna obtusifolia, Senna occidentalis. Oliveira et al., (2005) ao avaliarem o efeito de extratos das espécies Copaifera langsdorffii (Fabaceae) e Acacia bahiensis (Fabaceae), verificaram redução do comprimento radicular das plântulas de $L$. sativa, evidenciando ser esta a parte mais sensível à presença dos inibidores.

\section{Partição Líquido-Líquido}

A fração Acetato de etila foi mais efetiva na inibição da germinação e do crescimento de plântulas de L. sativa.

\section{Cromatografia Líquida de Alta Eficiência (HPLC)}

Para se identificar um metabólito secundário, o método mais comum é a comparação do seu tempo de retenção, na amostra a ser analisada, com o padrão desse mesmo composto. Segundo Ball (2006), cada composto é identificado por seu tempo de retenção, que depende de seu modo de interação com a fase estacionária. Assim, caso se verifique que o tempo de retenção (TR) da amostra coincida com o tempo de retenção do padrão, pode-se identificar o composto.
O cromatograma relativo à determinação dos compostos na amostra de $C$. ensiformis, no comprimento de onda a $220 \mathrm{~nm}$, está representado na Figura 2-A. O pico 1 apresentou $\mathrm{TR}=5,52 \mathrm{~min}$ e o pico $2, \mathrm{TR}=8,12 \mathrm{~min}$. Na figura 2-B, estão identificados os picos dos padrões puros ácido cafeico (1), quercetina (2) e kaempferol (3), neste mesmo comprimento de onda, $\operatorname{com} \mathrm{TR}=5,259 \pm 0,26 \mathrm{~min}, \mathrm{TR}=$ $6,691 \pm 0,33 \mathrm{~min}$ e $\mathrm{TR}=8,189 \pm 0,40 \mathrm{~min}$, respectivamente. Comparando-se o tempo de retenção da amostra de $C$. ensiformis, (Figura 2-A) com os picos dos padrões (Figura 2-B), pode-se verificar que o ácido cafeico e kaempferol são os picos 1 e 3, respectivamente. Não foi possível identificar o pico da quercetina (pico 2) na amostra de $C$. ensiformis.

No comprimento de onda de $270 \mathrm{~nm}$, o pico 1 da amostra de $C$. ensiformis obteve TR $=4,93$ min (Figura 2-C). Já para o padrão naringina, $\mathrm{TR}=5,048 \pm 0,25 \mathrm{~min}$ (Figura 2D). Pela comparação do tempo de retenção da amostra com o do padrão, pode-se confirmar que o pico 1 da amostra refere-se à naringina.

Os picos 1 e 2 da amostra de C. ensiformis (Figura 2-E) apresentaram TR $=4,891 \mathrm{~min}$ e TR $=5,570 \mathrm{~min}$, respectivamente, referentes ao comprimento de onda de $330 \mathrm{~nm}$. Os padrões puros de ácido clorogênico e ácido ferúlico demonstraram TR $=4,811 \pm 0,24$ min e $\mathrm{TR}=5,681 \pm 0,28 \mathrm{~min}$, respectivamente (Figura 2-F). Sendo assim, os picos da amostra de $C$. ensiformis (Figura 2-E) foram confirmados como sendo dos compostos ácido clorogênico (pico 1) e ácido ferúlico (pico 2), por comparação do tempo de retenção, semelhante ao dos padrões (Figura 2-F).

Tabela 1: Estimativas dos parâmetros a, b e c do coeficiente de determinação $\left(\mathrm{R}^{2}\right)$ do modelo log-logístico, para as espécies receptoras, nas variáveis germinação (G), índice de velocidade de germinação (IVG), comprimento de parte aérea (CPA) e comprimento radicular (CRA) das espécies receptoras, utilizando extrato etanólico de C. ensiformis

\begin{tabular}{|c|c|c|c|c|c|c|}
\hline \multirow{2}{*}{ Variável } & \multirow{2}{*}{ Espécie receptora } & \multicolumn{3}{|c|}{ Parâmetros $^{(1)}$} & \multirow{2}{*}{$\mathbf{R}^{(2)}$} & \multirow{2}{*}{$\mathbf{F}^{(3)}$} \\
\hline & & $\mathbf{a}$ & b & c & & \\
\hline \multirow{4}{*}{ G } & L. sativa & $99,22 * *$ & $1,24^{*}$ & 1,33 & 0,96 & 21,15 \\
\hline & D. insularis & $100,71 * *$ & $3,41 * *$ & $2,46 * *$ & 0,99 & 296,77 \\
\hline & E. coccínea & $96,27 * *$ & $4,39 *$ & 8,51 & 0,98 & 57,90 \\
\hline & P.oleraceae & $104,24 * *$ & $1,82 *$ & $4,77 *$ & 0,97 & 28,77 \\
\hline \multirow{4}{*}{ IVG } & L. sativa & $98,74 * *$ & $1,59 *$ & 1,32 & 0,97 & 25,83 \\
\hline & D. insularis & $99,98 * *$ & $3,57 * *$ & $2,32 * *$ & 0,99 & 732,35 \\
\hline & E. coccínea & $99,46 * *$ & 2,48 & $0,89 *$ & 0,97 & 24,33 \\
\hline & P.oleraceae & $100,64 * *$ & $6,56^{* *}$ & $3,78 * *$ & 0,99 & 281,84 \\
\hline \multirow{4}{*}{ CPA } & L. sativa & $103,32 * *$ & 5,99 & 18,53 & 0,99 & 138,07 \\
\hline & D. insularis & $88,19^{* *}$ & 5,90 & 14,48 & 0,98 & 71,33 \\
\hline & E. coccínea & $91,80 * *$ & $4,59 * *$ & 5,68 & 0,99 & 113,97 \\
\hline & P.oleraceae & $102,69 * *$ & $2,79 *$ & $1,59 *$ & 0,98 & 36,93 \\
\hline \multirow{4}{*}{ CRA } & L. sativa & $97,28 * *$ & $2,29 *$ & 1,61 & 0,97 & 33,26 \\
\hline & D. insularis & $101,69 * *$ & $2,67 * *$ & $2,52 * *$ & 0,99 & 242,22 \\
\hline & E. coccínea & $99,52 * *$ & $1,33^{*}$ & $1,31 *$ & 0,99 & 97,75 \\
\hline & P. oleraceae & $99,13 * *$ & $3,65^{*}$ & $1,61^{*}$ & 0,97 & 35,80 \\
\hline
\end{tabular}


O cromatograma referente ao comprimento de onda de $360 \mathrm{~nm}$, o tempo de retenção do pico 1 da amostra de $C$. ensiformis apresentou TR =5,237 min (Figura 2-G). Já para o padrão rutina, $\mathrm{TR}=5,220 \pm 0,26 \mathrm{~min}$ (Figura 2-H). Pela comparação do tempo de retenção da amostra com o do padrão, pode-se confirmar que o pico 1 da amostra é referente à rutina.

O pico da amostra de $C$. ensiformis apresentou TR = 8,136 min (Figura 3-A), analisado a $220 \mathrm{~nm}$. E os padrões ácido cítrico (pico 1), ácido malônico (pico 2) e ácido aspártico (pico 3), TR =7,978 $\pm 0,4$ min (Figura 3-B), TR = $8,019 \pm 0,4 \mathrm{~min}$ (Figura 3-C) e TR $=8,012 \pm 0,4 \mathrm{~min}$ (Figura 3-D), respectivamente. Por comparação do tempo de retenção do pico da amostra de C. ensiformis com os padrões, pode-se verificar que o ácido cítrico, malônico e aspártico estão presentes no mesmo pico da amostra.

Os metabólitos secundários ácidos fenólicos (ácido clorogênico, ácido ferúlico, ácido cafeico), flavonoides (rutina, naringina, kaempferol, quercetina) e ácidos carboxílicos (ácido malônico, ácido aspártico, ácido cítrico), identificados por meio da técnica da eletroforese capilar, foram encontrados nas raízes de C. ensiformis (Santos et al., 2007). Desses compostos, o ácido clorogênico, ácido ferúlico, rutina, naringina, kaempferol e ácido cafeico apresentaram maior inibição de germinação de plantas daninhas. Todos os metabólitos secundários identificados corroboram a presente pesquisa, para os compostos que foram analisados na parte aérea de C. ensiformis, com exceção da quercetina que não foi identificada. Assim, confirmou-se a presença dos ácidos fenólicos (ácido clorogênico, ácido ferúlico, ácido cafeico), flavonoides (kaempferol, naringina e rutina) e dos ácidos carboxílicos (ácido cítrico, ácido malônico e ácido aspártico), encontrados na literatura.

Ao avaliar os metabólitos secundários presentes nas sementes de C. ensiformis, por meio de cromatografia lí-
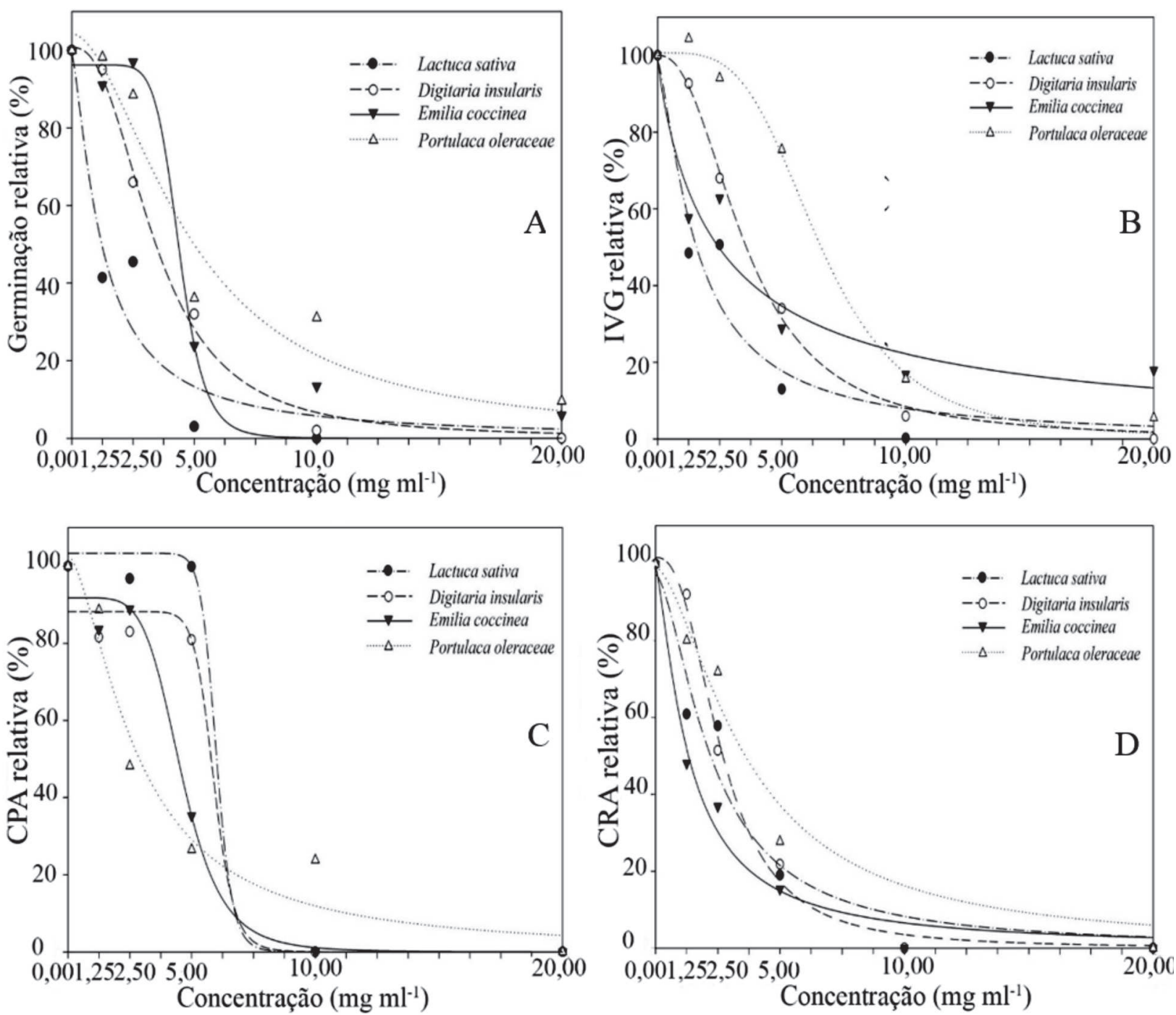

Figura 1: Percentagem de germinação (A), Índice de velocidade de germinação (B), Comprimento da parte aérea (C) e Comprimento radicular (D) das espécies receptoras em função das concentrações crescentes do extrato etanólico de C. ensiformis. 

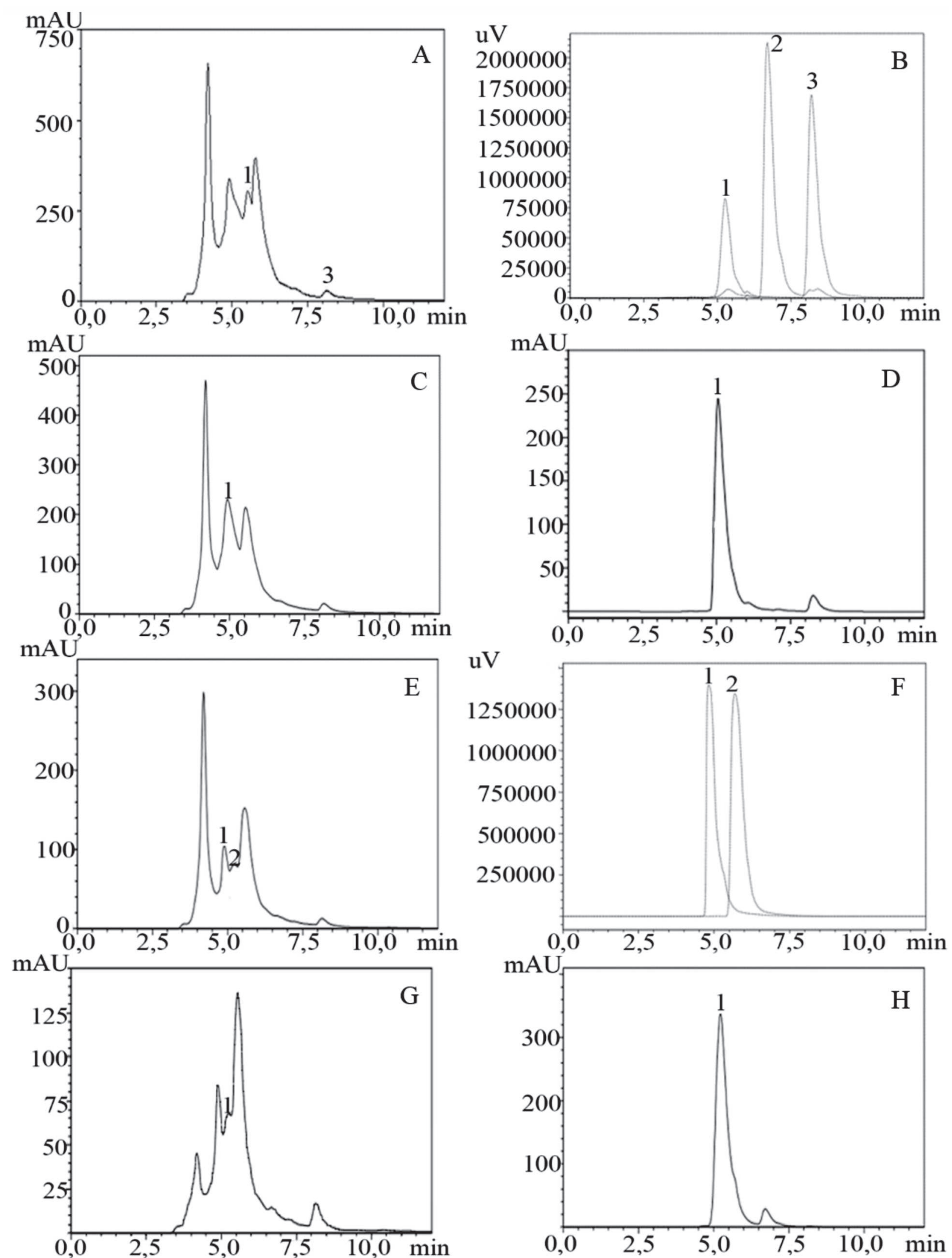

Figura 2: Cromatogramas da amostra de C. ensiformis (A) e padrões ácido cafeico (B-1), quercetina (B-2), kaempferol (B-3), com detector UV em $220 \mathrm{~nm}$; amostra de C. ensiformis (C) e padrão naringina (D-1), com detector UV em $270 \mathrm{~nm}$; amostra de $C$. ensiformis (E) e padrões ácido clorogênico (F-1) e ácido ferúlico (F-2), com detector UV em $330 \mathrm{~nm}$; amostra de C. ensiformis (G) e padrão rutina (H-1), com detector UV em $360 \mathrm{~nm}$ com fluxo de 1,0 mL min-1 e fase móvel composta por ácido fosfórico $0,1 \%$ e metanol (80:20). 
quida de alta eficiência, Mendonça (2008) verificou a existência do ácido clorogênico, ácido ferúlico, ácido p-anísico e genisteína, causando efeito alelopático no desenvolvimento das plântulas de Commelinna benghalensis e Ipomoea grandifolia. Mendes \& Rezende (2014) também identificaram os compostos ácido clorogênico, naringina e rutina em folhas de $C$. ensiformis, corroborando os resultados deste estudo, pois também foi identificada a presença de ácido clorogênico, naringina e rutina.

Os flavonoides têm grande variedade de funções fisiológicas nas plantas (Peer et al., 2001). Apresentam funções de pigmentos, atrativos ou repelentes de herbívoros, ações antimicrobianas, afetam a germinação do tubo polínico, atuam na proteção contra radiação UV, influenciam no transporte de auxinas, modulam os níveis das espécies reativas de oxigênio (EROS) e apresentam efeitos alelopáticos, sendo capazes de inibir a germinação e o crescimento das plantas (Shimoji \& Yamasaki, 2005; Hoagland \& Williams, 2004; Bais et al., 2006; Peer \& Murphy, 2007).

Foi identificado a presença dos flavonoides (kaempferol e quercetina), no extrato de Copaifera langsdor-ffii (Fabaceae), e houve uma redução da germinação e do crescimento de plântulas de Sorghum bicolor, quando submetidas ao extrato contendo esses compostos (Franco et al., 2016). Flavonoides (rutina e quercetina) e ácidos fenólicos (ácido clorogênico e ácido cafeico) foram encontrados por Golisy et al., (2007), na espécie Fagopyrum esculentum (Polygonaceae), causando efeito alelopático em L. sativa, sendo a rutina a principal responsável pela inibição de crescimento das plântulas.

Extrato de Eragrostis plana Nees (Poaceae) inibiu a germinação de sementes, o índice de velocidade de ger- minação e o desenvolvimento inicial das plântulas, em todas as espécies testadas, e identificou-se a presença de compostos fenólicos (ácido cafeico, ácido clorogênico) e flavonoides (rutina), sendo possivelmente o efeito alelopático causado por esses metabólitos secundários (Fiorenza et al., 2016). Esses resultados corroboram os dados de inibição das espécies receptoras, quando submetidas ao extrato de $C$. ensiformis e os compostos identificados neste estudo, comprovando que o efeito alelopático pode ser devido à presença desses metabólitos secundários.

Os ácidos fenólicos atuam induzindo o aumento da atividade de enzimas oxidativas, causando assim a modificação da permeabilidade da membrana e a formação de lignina, contribuindo para a redução do crescimento radicular (Ferrarese et al., 2000). Oliveira et al., (2011) relataram que o ácido clorogênico inibiu a germinação e o crescimento das plântulas de Bidens pilosa e Brachiaria brizantha, confirmando seu efeito alelopático. Chon \& Kim (2002) observaram que o extrato foliar de Medicado sativa L. (Fabaceae) apresentou maior inibição do crescimento radicular e, dentre os compostos identificados, estão o ácido ferúlico e ácido cafeico. Loffredo et al., (2005) relataram que ácido cafeico e ácido ferúlico apresentam efeito alelopático e inibem a germinação e o crescimento de plântulas de L. sativa e Lycopersicon esculetum. Bubna et al., (2011) verificaram que o ácido cafeico aumentou a formação dos monômeros de ligninas, solidificou a célula da parede celular e,assim, inibiu o crescimento radicular de Glycine max. Em vista desses relatos, pode-se inferir que os ácidos fenólicos encontrados na parte aérea de $C$. ensiformis, contribuíram para a redução da germinação e do comprimento de plântulas, nas espécies receptoras analisadas.
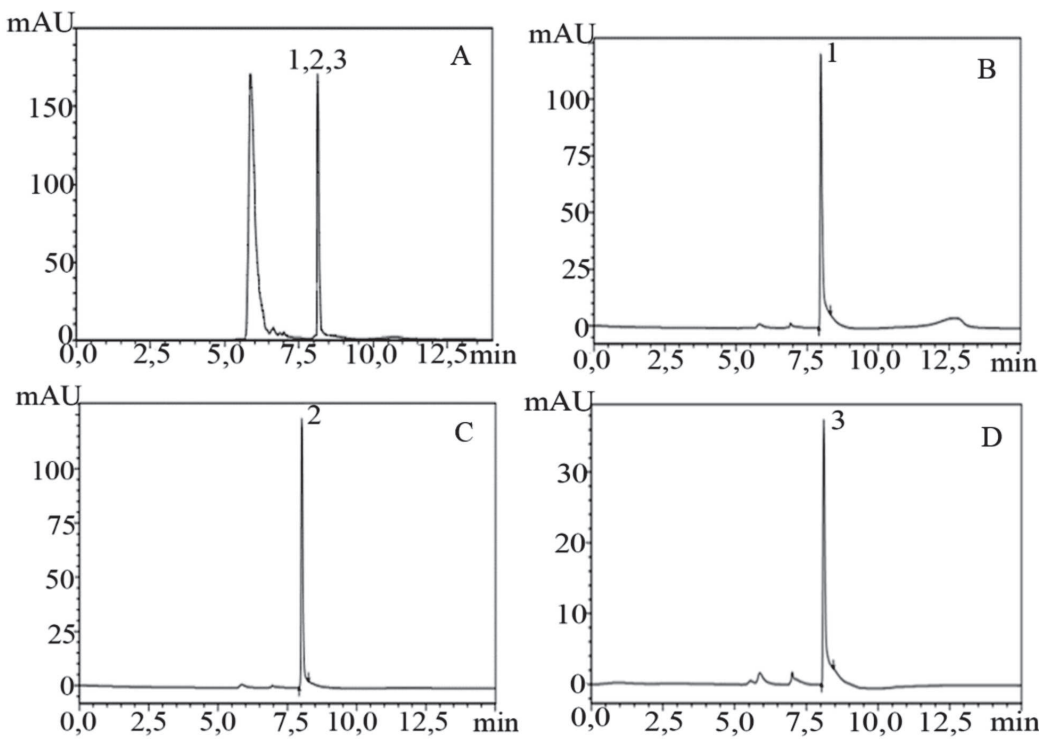

Figura 3: Cromatogramas da amostra de $C$. ensiformis (A) e padrões ácido cítrico (B-1), ácido malônico (C-1) e ácido aspártico (D1), com detector UV em $220 \mathrm{~nm}$, com fluxo de 1,0 mL min-1 e fase móvel composta por 10mM KH2PO4: CH3OH (95:5). 
Em relação aos ácidos carboxílicos, Santos et al., (2011), utilizando a técnica de eletroforese capilar, identificaram os compostos ácido malônico, ácido aspártico e ácido cítrico, em plantas de Calopogonium mucunoides (Fabaceae). Ao observarem a inibição da germinação de plantas submetidas a esses compostos, verificaram que o ácido aspártico não causou nenhum efeito e o ácido cítrico causou maior inibição da germinação de Mimosa pudica. De acordo com esse resultado, o ácido cítrico encontrado nesse experimento pode ter causado algum efeito alelopático.

Associando-se os dados da literatura sobre a ação de cada metabólito secundário na planta, com os compostos encontrados neste estudo, é possível inferir que a inibição da germinação e a redução do crescimento de plântulas das espécies receptoras receptoras podem ser devidas à interferência dos compostos pertencentes ao grupo dos flavonoides, ácidos fenólicos e ácidos carboxílicos, encontrados na parte aérea de C. ensiformis, sendo necessários mais estudos para avaliar se eles atuam de forma isolada ou sinergicamente.

\section{CONCLUSÕES}

O extrato etanólico de $C$. ensiformis causa inibição da germinação e do índice de velocidade de germinação de Lactuca sativa. A parte aérea de $C$. ensiformis contém ácidos fenólicos (ácido clorogênico, ácido ferúlico, ácido cafeico), flavonoides (kaempferol, naringina e rutina) e ácidos carboxílicos (ácido cítrico, ácido malônico e ácido aspártico), que podem ser os responsáveis pela atividade alelopática dessa espécie.

\section{REFERÊNCIAS}

Al-Sherif E, Hegazy AK, Gomma NH \& Hassan MO (2013) Allelopathic effect of black mustard tissues and root exudates on some crops and weeds. Planta Daninha, 31:11-19.

Bais HP, Weir TL, Perry LG, Gilroy S \& Vivanco JM (2006) The role of root exudates in rhizosphere interactions with plants and other organisms. Annual Review of Plant Biology, 57:233-266.

Ball GFM (2006) Vitamins in foods: Analysis, bioavailability, and stability. Boca Raton, CRC Press. 785p.

Blum U (1995) The value of model plant-microbe-soil systems for understanding processes associated with allelopathic interaction: one example. In: Dakshini IKMM \& Einhellig FA (Eds) Allelopathy: Organisms, Processes, and Applications. Washington, American Chemical Society. p.127-131.

Borghetti F \& Ferreira AG (2004) Interpretação de resultados de germinação. In: Ferreira AG \& Borghetti F (Eds.) Germinação - do básico ao aplicado. Porto Alegre, Artmed. p.209-222.

Brasil (2009) Regras para análise de sementes. Brasília, Mapa/ ACS. 395p.

Bubna GA, Lima RB, Zanardo DYL, Santos WD, Ferrarese MDLL \& Ferrarese-Filho O (2011) Exogenous caffeic acid inhibits the growth and enhances the lignification of the roots of soybean (Glycine max). Journal of Plant Physiology, 168:1627-1633.
Buer CS \& Djordjevic MA (2009) Architectural phenotypes in the transparent test a mutants of Arabidopsis thaliana. Journal of Experimental Botany, 60:751-763.

Calegari A (1995) Leguminosas para adubação verde no Paraná. Londrina, IAPAR. 118p. (Circular, 80).

Cavalcanti NB (2011) Influência de diferentes substratos na emergência e crescimento de plantas de feijão de porco (Canavalia ensiformis L.). Engenharia Ambiental, 8:51-70.

Chon SU \& Kim JD (2002) Biological activity and quantification of suspected allelochemicals from alfalfa plant parts. Journal of Agronomy and Crop Science, 188:281-285.

Chon SU, Nelson CJ \& Coutts JH (2003) Physiological assessment and path coefficient analysis to improve evaluation of alfalfa autotoxicity. Journal of Chemical Ecology, 29:2413-2424.

Christoffoleti PJ (2002) Curvas de dose-resposta de biótipos resistente e suscetível de Bidens pilosa L. aos herbicidas inibidores da ALS. Scientia Agricola, 59:513-519.

Christoffoleti PJ \& López-Ovejero RF (2008) Resistência das plantas daninhas a herbicidas: definições, bases e situação no Brasil e no mundo. In: Christoffoleti PJ (Ed.) Aspectos de resistência de plantas daninhas a herbicidas. $3^{\mathrm{a}}$ ed. Piracicaba, HRACBR. p.03-30.

Collins CH, Braga GL \& Bonato OS (2006) Fundamentos de Cromatografia. Campinas, UNICAMP. 452p.

Ding J, Wang X, Zhang XW, Li Q \& Luo M (2006) Optimization of RP-HPLC Analysis of Low Molecular Weight Organic Acids in Soil. Journal of Liquid Chromatography \& Related Technologies, 29:99-112.

Ferrarese MLL, Souza NE, Rodrigues JD \& Ferrarese Filho O (2000) Carbohydrate and lipid status in soybean roots influenced by ferulic acid uptake. Acta Physiologiae Plantarum, 23:421-427.

Ferreira AG \& Áquila MEA (2000) Alelopatia: uma área emergente da ecofisiologia. Revista Brasileira de Fisiologia Vegetal, 12:175-204.

Fiorenza M, Dotto DB, Bolignon AA, Bolignon AA, Atahyde ML \& Vestena S (2016) Análise ûtoquímica e atividade alelopática de extratos de Eragrostis plana Nees (capim-annoni). Iheringia, 71:193-200.

Franco DM, Saldanha LL, Neto JSL, Santos LC, Dokkedal AL \& Almeida LFR (2016) Seasonal variation in allelopathic potential of the leaves of Copaifera langsdorffii Desf. Acta Botanica Brasilica, 30:157-165.

Golisy A, Lata B, Gawronski S \& Fujii Y (2007) Specific and total activities of the allelochemicals identified in buckwheat. Weed Biology and Management, 7:164-171.

Hagemann TR, Benin G, Lemes C, Marchese JA, Martin TN, Pagliosa ES \& Beche E (2010) Potencial alelopático de extratos aquosos foliares de aveia sobre azevém e amendoimbravo. Bragantia, 69:509-518.

Hajimehdipoor H, Kondori BM, Amin GR, Adib N, Rastegar H \& Shekarch M (2012) Development of a validated HPLC method for the simultaneous determination of flavonoids in Cuscuta chinensis Lam. by ultra-violet detection. Journal of Pharmaceutical Science, 20:01-06.

Hoagland RE \& Williams RD (2004) Bioassays-useful tolls of the study of allelopathy. In: Macias FA, Galindo JCG, Molinillo JMG \& Cutler HG (Eds.) Allelopathy: Chemistry and mode of action of allelochemicals. Boca Raton, CRC Press. p.315-41.

Jabran K \& Farooq M (2013) Implications of potential allelopathic crops in agricultural systems. In: Cheema ZA, Farooq M \& Wahid A (Eds.) Allelopathy Current Trends and Future Applications. New York, Springer-Verlag. p. 349-385. 
Larcher W (2000) Ecofisiologia Vegetal. São Carlos, Rima Artes e Textos. $531 \mathrm{p}$.

Lessa BFT, Ferreira VM, Araújo Neto JC \& Souza RC (2013) Germinação de sementes de Emilia coccinea (Sims) G. don em função da luminosidade, temperatura, armazenamento e profundidade de semeadura. Semina, 34:3193-3204.

Loffredo E, Monaci L \& Senesi N (2005) Humic Substances Can Modulate the Allelopathic Potential of Caffeic, Ferulic, and Salicylic Acids for Seedlings of Lettuce (Lactuca sativa L.) and Tomato (Lycopersicon esculentum Mill.). Journal of Agricultural and Food Chemistry, 53:9424-9430.

Maguire JD (1962) Speeds of germination-aid selection and evaluation for seedling emergence and vigor. Crop Science, $2: 176-177$.

Marinov-Serafimov P (2010) Determination of allelopathic effect of some invasive weed species on germination and initial development of grain legume crops. Pesticides \& Phytomedicine, 25:251-259.

Mendes IDS \& Rezende MAO (2014) Assessment of the allelopathic effect of leaf and seed extracts of Canavalia ensiformis as postemergent bioherbicides: A green alternative for sustainable agriculture. Journal of Environmental Science and Health, 49:374-380.

Mendonça R (2008) Determinação de aleloquímicos por HPLC/ UV-Vis em extratos aquosos de sementes de Canavalia ensiformis e estudo da atividade alelopática. Dissertação de Mestrado. Universidade de São Paulo, São Carlos. 82p.

Oliveira MNS, Simoes MOM, Ribeiro LM, Lopes PSN, Gusmão E \& Dias BAS (2005) Efeitos alelopáticos de seis espécies arbóreas da família Fabaceae. Unimontes Científica, 7:121-128.

Oliveira PVA, França SC, Bregagnoli M \& Pereira OS (2011) Avaliação alelopática de Tithonia diversifolia na germinação e no crescimento inicial de Bidens pilosa e Brachiaria brizantha. Revista Agroambiental, 3:23-30.

Peer DE, Brown BW, Tague GK, Muday L \& Murphy TAS (2001) Flavonoid accumulation patterns of transparent testa mutants of Arabidopsis. Plant Physiology, 126:536-548.

Peer WA \& Murphy AS (2007) Flavonoids and auxin transport: modulators or regulators? Trends in Plant Science, 12:556563.
Rice EL (2013) Allelophathy. New York, Academic press. p. 421.

Santos S, Moraes MLL \& Rezende MOO (2007) Allelopathic potential and systematic evaluation of secondary compounds in extracts from roots of Canavalia ensiformis by capillary electrophoresis. Eclética Química, 32:13-18.

Santos S, Moraes MLL, Rezende MOO \& Souza Filho APS (2011) Potencial alelopático e identificação de compostos secundários em extratos de calopogônio (Calopogonium mucunoides) utilizando eletroforese capilar. Eclética Química, 36:51-68.

Santos S, Moraes MLL, Souza Filho APS \& Rezende MOO (2005) Allelopathic Potential and Systematic Evaluation of Organic Extracts trom Canavalia ensiformis Leaves (Jack Beans). Journal of Emironmenlat Science and Heallh, 40:77-84.

Shahidi F \& Naczk M (1995) Food phenolics: sources, chemistry, effects and applications. Lancaster, Technomic. 331p.

Shimoji H \& Yamasaki H (2005) Inhibitory effects of flavonoids on alternative respiration of plant mitochondria. Biologia Plantarum, 49:117-119.

Silva RMG, Saraiva TS, Silva RB, Gonçalves LA \& Pereira L (2010) Potencial alelopático de extrato etanólico de Anadenanthera macrocarpa e Astronium graveolens. Bioscience Journal, 26:632-637.

Souza Filho APS (2002) Atividade potencialmente alelopática de extratos brutos e hidroalcoolicos de feijão-de-porco (Canavalia ensiformis). Planta Daninha, 20:357-364.

Streibig JC (1988) Herbicide bioassay. Weed Research, 28:497484.

Taiz L \& Zeiger E (2013) Fisiologia vegetal. 5 ${ }^{\text {a }}$ ed. Porto Alegre, Artmed. 954p.

Taveira LKPD, Silva MAP \& Loiola MIB (2013) Allelopathy in five species of Erythroxylum. Acta Scientiarum, 35:325-331.

Weir TL, Park SW \& Vivanco JM (2004) Biochemical and physiological mechanisms mediated by allelochemicals. Current Opinion in Plant Biology, 7:472-479.

Zeng RS (2014) Allelopathy - the solution is indirect. Journal of Chemical Ecology, 40:515-516.

Zimdahl RL (2007) Fundamentals of Weed Science, $3^{\mathrm{a}}$ ed. London, Academic Press. 666p. 